\title{
Evidence of natural hybridization in Brachiaria humidicola (Rendle) Schweick. (Poaceae: Panicoideae: Paniceae)
}

\author{
KELLEN REGINA BOLDRINI ${ }^{1}$, M. S. PAGLIARINI ${ }^{1}$ and C. B. VALLE ${ }^{2}$ \\ ${ }^{1}$ Department of Cell Biology and Genetics, State University of Maringá, 87020-900 Maringá Paraná, Brazil \\ ${ }^{2}$ Embrapa Beef Cattle, P.O. Box 154, 79002-970 Campo Grande, Mato Grosso do Sul, Brazil
}

\section{Introduction}

Polyploidy and aneuploidy are conspicuous features of chromosomal evolution in the Poaceae; at least $80 \%$ of grass species are of polyploid origin (Stebbins 1985). The original basic chromosome number for the Poaceae is not known and has been the subject of much speculation. In the large tribe Paniceae, which includes the genus Brachiaria, the most common basic chromosome number is $x=9$ (De Wet 1986). The predominance of $x=9$ in Brachiaria genus had been reported in several studies (Basappa et al. 1987; Honfi et al. 1990; Bernini and Marin-Morales 2001; Mendes-Bonato et al. 2002, 2006; Utsunomiya et al. 2005). More recently, a new chromosome number, $x=6$, was determined for $B$. dictyoneura (Risso-Pascotto et al. 2006). There is a large predominance of polyploid forms in the genus Brachiaria and tetraploids prevail. The origin of polyploidy, however, has never been pursued in this genus. Cytological evidence from analysis of meiotic behaviour, including chromosome pairing at diakinesis, led to the suggestion that autotetraploidy and segmental allopolyploidy could have contributed to evolution in some species (Mendes-Bonato et al. 2002, 2006; Utsunomiya et al. 2005). On the other hand, in two pentaploid accessions of $B$. brizantha $(2 n=5 x=45)$ there was clear evidence of allopolyploidy (Mendes et al. 2006). This paper reports the unusual cytological behaviour during meiosis in one accession of Brachiaria humidicola from the Embrapa Beef Cattle germplasm collection.

\section{Materials and methods}

The accession under analysis (H003, BRA004812) was collected in wild African savannas, in the region of Sidamo (Ethiopia), by the International Center for Tropical

*For correspondence. E-mail: mspagliarini@uem.br.
Agriculture (CIAT, Cali, Colombia), in 1984-1985. Inflorescences for meiotic study were prepared according to Boldrini et al. (2006).

\section{Results}

More than 1800 meiocytes were analysed in this accession for microsporogenesis evaluation. Chromosome counting in diakinesis in some cells presenting only univalents (figure 1a), in cells in typical diakinesis (figure 1b), and in cells in anaphase I (figure 1,c-e) revealed 42 chromosomes. The percentage of meiotic abnormalities varied among phases (table 1). The main abnormalities were related to irregular chromosome segregation that followed a particular pattern. During diakinesis, in the majority of cells, 12 univalents could be counted (figure 1b). Twelve univalent chromosomes not aligned at the plate (figure 1d) were recorded in metaphase I. In anaphase I, however, the meiocytes showed a set of 12 univalents in the metaphase plate (figure 1e), while the genome of 30 chromosomes segregated as 15 chromosomes moving towards each pole (figure $1, \mathrm{e} \& \mathrm{f}$ ). In this phase, $81.4 \%$ of meiocytes exhibited the laggard genome. Subsequently, the univalent chromosomes underwent sisterchromatid segregation whereas the segregated chromosomes reached the poles (figure 1,f-h). Telophase nuclei sometimes presented abnormal shape (figure 1i). This behaviour was repeated in the second division: some meiocytes displayed some chromosomes not aligned in the metaphase plate, but in the majority of the cells the chromosome behavior was normal (figure $1 \mathrm{j}$ ). In anaphase II, while one group of chromosomes underwent normal sister-chromatid segregation, the sister-chromatids segregated in anaphase I remained as laggards (figure 1,k and l). The migration of these chromatids remained asynchronous in relation to the other genome (figure $1 \mathrm{~m}$ ) and they gave rise again to abnormally shaped nuclei in early telophase II (figure $1 \mathrm{n}$ ). In late telophase and tetrad

Keywords. allopolyploidy; forage grass; genome affinity; meiotic rhythm; Brachiaria humidicola. 
(figure 1,o\&p), the abnormal shape of the nucleus was not more apparent, and less than $5 \%$ of the tetrads presented micronuclei.

\section{Discussion}

Asynchronous meiosis, such as found in the accession H003, had been reported in the genus Brachiaria by Risso-Pascotto et al. (2004) in an interspecific triploid hybrid between $B$. brizantha $(2 n=4 x=36$, apomictic) and B. ruziziensis ( $2 n=2 x=18$, sexual). The asynchrony was evident during all stages of microsporogenesis. The genome of $B$. ruziziensis always behaved as laggard in relation to the genome of $B$. brizantha and was eliminated as micronuclei at the end of meiosis. Mendes et al. (2006) observed a similar behaviour

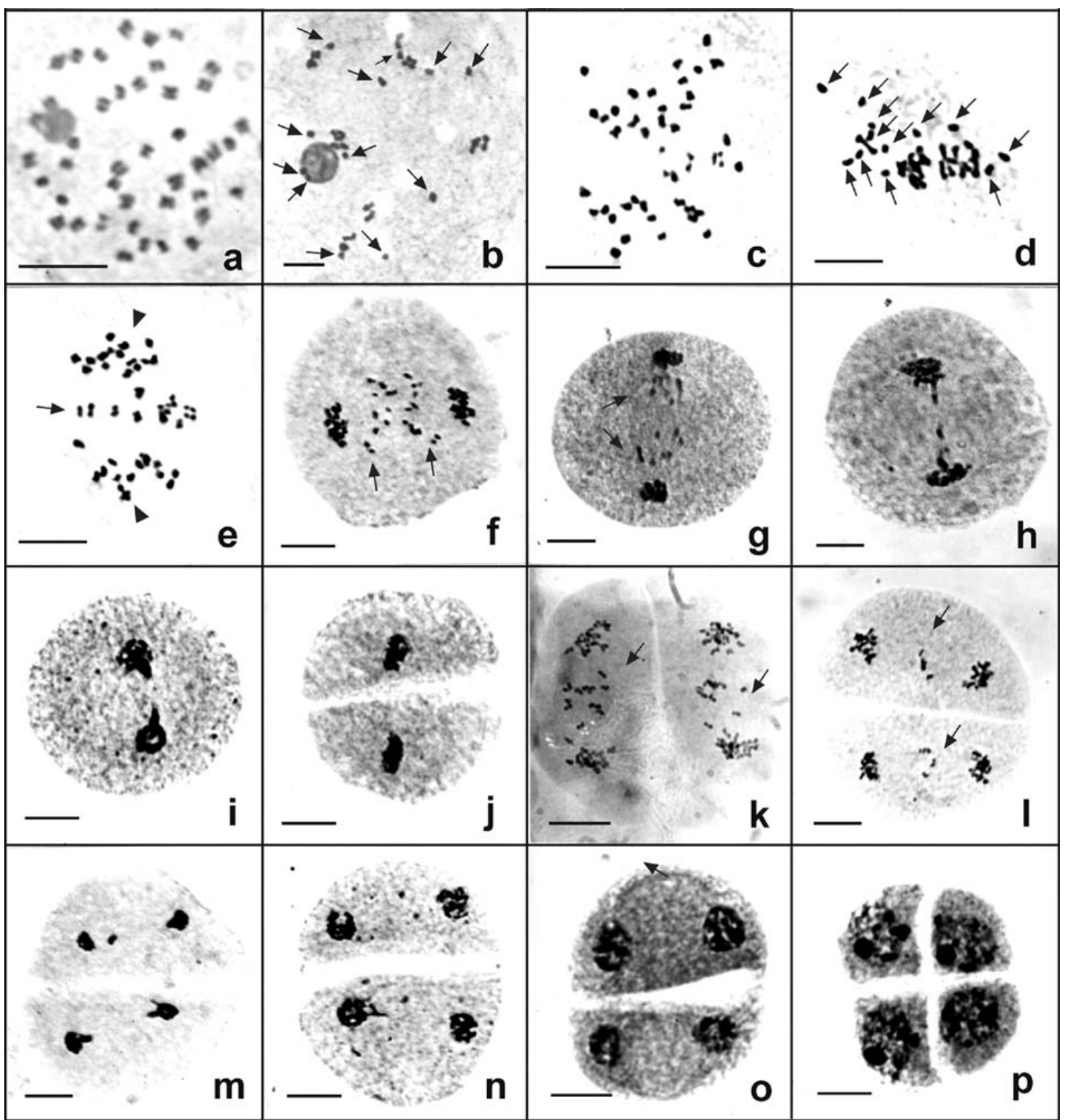

Figure 1. (a) Meiocytes in diakinesis showing 42 univalents. (b) Typical diakinesis with 12 univalents (arrows) and bivalents. (c) Anaphase I with 42 chromosomes. (d) Metaphase I showing 12 non-congregated univalents (arrows). (e) Anaphase I with a laggard genome with 12 univalents (arrows) in the metaphase plate and 15 segregated chromosomes in each pole (arrowheads). (f) Anaphase I with 12 laggard segregated sister-chromatids migrating to each pole (arrows). (g) Early telophase I with the laggard genome in anaphase I. (h and i) Telophase I showing the inclusion of the laggard genome in the nuclei. (j) Normal metaphase II. ( $\mathrm{k}$ and $\mathrm{l}$ ) Anaphase II showing the laggard genome. In $\mathrm{k}$ it is possible to visualize the 12 sister-chromatids of the laggard genome (arrows). ( $m$ and $n$ ) Telophase II with irregular nucleus shape due to the laggard chromosomes. (o) Normal telophase II. (p) Normal tetrad of microspores. (Scale bars $=19 \mu \mathrm{m}$ ). 
Table 1. Percentage of meiotic abnormalities observed in the accession H003.

\begin{tabular}{lcl}
\hline Phase & No. of cells analysed & Abnormalities, no. of cells (\%) \\
\hline Metaphase I & 218 & Univalents at metaphase plate, 54 (24.77) \\
Anaphase I & 247 & Laggard genome, 201 (81.37) \\
Telophase I & 277 & Abnormal nucleus shape, 61 (22.02) \\
Prophase II & 131 & Micronuclei, 4 (3.05) \\
Metaphase II & 224 & Precocious chromosome migration, 34 (15.17) \\
Anaphase II & 330 & Laggard sister-chromatids, 125 (37.87) \\
Telophase II & 269 & Abnormal nucleus shape, 55 (20.44) \\
Tetrad & 163 & Micronuclei, 8 (4.90) \\
\hline
\end{tabular}

in two pentaploid accessions $(2 n=5 x=45)$ of $B$. brizantha. These pentaploid accessions were also probably originated by natural hybridization between two distinct genomes with different meiotic rhythms. Pentaploidy was probably the result of the union of an apomictic tetraploid genitor $(2 n=4 x=36)$ and a sexual diploid one $(2 n=2 x=18)$. The chromosomes in the gametes of the diploid genitor $(n=9)$ always remained as univalents in prophase I, underwent sisterchromatid segregation in anaphase I, and remained as laggard. The haploid genome was always included peripherally in the nucleus, changing the nucleus shape in telophase I. In the second division, the behaviour was repeated. However, the chromatids from the first division did not reach the poles in time to be included in the nucleus, giving rise to several micronuclei. In $\mathrm{H} 003$, the behaviour was similar. In diakinesis, 12 univalents could be counted and they were late in profiling at the metaphase plate. In anaphase I and II, they typically behaved as laggards, however, they managed to reach the poles and were included in the nuclei, sometimes changing the nucleus shape, but never remaining as micronuclei. Whereas in the two cases above (Risso-Pascotto et al. 2004; Mendes et al. 2006), the haploid genome was eliminated from the microspores, in this accession of $B$. humidicola, the laggard genome was always included in the nuclei of the tetrad.

Two basic chromosome numbers, $x=7$ and $x=9$, have been reported for the genus Brachiaria (Basappa et al. 1987; Honfi et al. 1990; Bernini and Marin-Morales 2001; MendesBonato et al. 2002, 2006; Utsunomiya et al. 2005), but recently a new number $(x=6)$, was determined for several accessions of $B$. dictyoneura (Risso-Pascotto et al. 2006). One possibility is that H003 is a hexaploid $(2 n=6 x=42)$ derived from $x=7$, since this basic number has been reported quite frequently in the genus Brachiaria. However, the constant presence of 12 univalents in diakinesis that remained as laggard in anaphase I, and then segregated as sister-chromatids, together with the fact that the remaining 30 chromosomes segregated as 15 chromosomes towards each pole in anaphase I and II respectively, strongly suggests a different origin for this accession. Possibly this accession is a heptaploid, derived from $x=6$, and its genomic constitution is $2 n=7 x=42$. As mentioned above, $x=6$ was reported in B. dictyoneura (Risso-Pascotto et al. 2006), a species suggested to belong to the same agamic complex as B. humidicola (Renvoize et al. 1996).

Brachiaria dictyoneura and B. humidicola are similar in morphology and vegetative traits and, at times, have been confused by agronomists. According to Renvoize $e t$ al. (1996), the taxonomy of Brachiaria genus is far from satisfactory. After a revision of 97 species of the genus, spanning the whole taxon, the species were arranged in nine groups according to distinct morphological traits and natural affinities. Brachiaria humidicola and $B$. dictyoneura belong to the same group (group 6). If this accession is really a heptaploid derived from $x=6$, one explanation must be sought for the 12 univalents instead of the expected six for a basic number $x=6$. All accessions of $B$. dictyoneura cytologically analysed in this collection were tetraploid $(2 n=4 x=24)$, derived from $x=6$ (Risso-Pascotto et al. 2006). The meiotic behaviour in these accessions was practically normal with only a few multivalents recorded. The percentage of abnormal tetrads was less than $12 \%$. Indeed, they behaved as diploidized tetraploids. Thus, gametic chromosome constitution with $n=12$ was expected. If so, one genitor could have contributed with $2 n=5 x=30$ chromosomes and the other with $n=x=12$ in the case of H003.

Harlan and De Wet (1975) demonstrated that polyploids arise in nature through sexual functioning of cytologically unreduced gametes. The unreduced female gamete is fertilized by a haploid sperm to produce a triploid offspring. Triploids are male sterile but produce functional, cytologically unreduced female gametophytes. When triploids are pollinated by the original male parent, tetraploid offspring are produced. According to De Wet (1986), the production of cytologically unreduced eggs not only favors polyploidization, but also facilitates interspecific hybridization by buffering the maternal genotype against the shock of absorbing the alien genome. Several species produces a variable number of unreduced gametes (Bretagnolle and Thompson 1995). In the genus Brachiaria, the occurrence of cytologically unreduced microspores, mainly by abnormal first and second cytokinesis in different species of $B$. brizantha (Risso-Pascotto et al. 2003), B. nigropedata (Utsunomiya et al. 2005) and B. jubata (Mendes-Bonato et al. 2006), were recently reported by 


\section{Kellen Regina Boldrini et al.}

our group, and also in the present accession of $B$. humidicola (Boldrini et al. 2006). However, unreduced eggs have never been reported in the genus Brachiaria.

According to Stebbins (1985), successful polyploids combine the genotypes of differently adapted populations belonging to the same species or closely related species. Stebbins (1985) also emphasized that for newly evolved polyploids to succeed their gene pools need to be expanded by mutation or secondary hybridization. True allopolyploids commonly originate from hybridization at the tetraploid or higher ploidy levels. This may involve interspecific as well as intergeneric hybridization (De Wet 1986). The cytological behaviour during microsporogenesis of $\mathrm{H} 003$ clearly suggests the occurrence of hybridization between two genitors of different ploidy levels, of an uncommon basic number and especially with different meiotic rhythms, mainly in the timing of anaphase.

Brachiaria humidicola is a species originally found in water margins and poorly drained soils of Africa. One cultivar is widely used as pasture in Brazil and elsewhere in the tropics, especially in acid and drainage deficient areas (Keller-Grein et al. 1996). The knowledge about chromosome number and meiotic behaviour is essential to accomplish crosses among $B$. humidicola accessions with desirable agronomic characters. Although the present accession has no practical value for breeding due to its unusual chromosome number and meiotic behaviour, it serves as an important function in the study of the origin of polyploidy series in this species and in the genus.

\section{Acknowledgements}

Authors are grateful to UNIPASTO for financial support.

\section{References}

Basappa G. P., Muniyamma M. S. and Chinnappa C. C. 1987 An investigation of chromosome numbers in the genus Brachiaria (Poaceae:Paniceae) in relation to morphology and taxonomy. Can. J. Bot. 65, 2297-2309.

Bernini C. and Marin-Morales M. A. 2001 Karyotype analysis in Brachiaria (Poaceae) species. Cytobios 104, 157-171.

Boldrini K. R., Pagliarini M. S. and Valle C. B. 2006 Abnormal timing of cytokinesis in microsporogenesis of Brachiaria humidicola (Poaceae: Paniceae). J. Genet. 85, 225-228.
Bretagnolle F. and Thompson J. D. 1995 Gametes with the somatic chromosome number: mechanisms of their formation and role in the evolution of autopolyploid plants. New Phytol. 129, 1-22.

De Wet J. M. J. 1986 Hybridization and polyploidy in the Poaceae. In Grass: systematics and evolution (ed. T. R. soderstrom, T. R. Hilu, W. H. Campbell and M. E. Barkworth), pp. 179-187. Smithsonian Institution Press, Washington DC, USA.

Harlan J. R. and De Wet J. M. J. 1975 On Ö Winge and a prayer: the origins of polyploidy. Bot. Rev. 41, 361-390.

Honfi A. I., Quarin C. L. and Valls J. F. M. 1990 Estudios cariologicos en gramineas sudamericanas. Darwiniana 30, 87-94.

Keller-Grein G., Maass B. L. and Hanson J. 1996 Natural variation in Brachiaria and existing germoplasma collections. In Brachiaria: biology, agronomy, and improvement (ed. J. W. Miles, B. L. Maass and C. B. Valle), pp. 17-42, CIAT/EMBRAPA, Cali, Colombia.

Mendes D. V., Boldrini K. R., Mendes-Bonato A. B., Pagliarini M. S. and Valle C. B. 2006 Cytological evidence of natural hybridization in Brachiaria brizantha Stapf (Gramineae). Bot. J. Linn. Soc. 150, 441-446.

Mendes-Bonato A. B., Pagliarini M. S., Forli F., Valle C. B. and Penteado M. I. O. 2002 Chromosome number and microsporogenesis in Brachiaria brizantha (Gramineae). Euphytica 125, 419425.

Mendes-Bonato A. B., Pagliarini M. S., Risso-Pascotto C. and Valle C. B. 2006 Chromosome number and meiotic behavior in Brachiaria jubata (Gramineae). J. Genet. 85, 83-88.

Renvoize S. A., Clayton W. D. and Kabuye C. H. S. 1996 Morphology, taxonomy, and natural distribution of Brachiaria (Trin.) Griseb. In Brachiaria: biology, agronomy, and improvement (ed. J. W. Miles, B. L. Maass and C. B. Valle), pp. 1-15, CIAT/EMBRAPA, Cali, Colombia.

Risso-Pascotto C., Pagliarini M. S., Valle C. B. and Mendes-Bonato A. B. 2003 Chromosome number and microsporogenesis in pentaploid accession of Brachiaria brizantha (Gramineae). Plant Breed. 122, 136-140.

Risso-Pascotto C., Pagliarini M. S. and Valle C. B. 2004 Asynchronous meiotic rhythm as the cause of selective chromosome elimination in an interspecific Brachiaria hybrid. Plant Cell Rep. 22, 945-950.

Risso-Pascotto C., Pagliarini M. S. and Valle C. B. 2006 A new basic chromosome number for the genus Brachiaria (Trin.) Griseb. (Poaceae: Panicoideae: Paniceae). Genet. Res. Crop. Evol. 53, 7 10.

Stebbins G. L. 1985 Polyploidy, hybridization and the invasion of new habitats. Ann. Miss. Bot. Gard. 72, 824-832.

Utsunomiya K. S., Pagliarini M. S. and Valle C. B. 2005 Microsporogenesis in tetraploid accessions of Brachiaria nigropedata (Ficalho \& Hiern) Stapf (Gramineae). Biocell 29, 295-301. 